\title{
The influence of the mineral additives on the carbonation of cement composites
}

\author{
Pawet Woliński ${ }^{1,}{ }^{*}$, Piotr Woyciechowski ${ }^{1}$, Beata Jaworska ${ }^{1}$, Grzegorz Adamczewski ${ }^{1}$, \\ Daniel Tokarski ${ }^{2}$, Tomasz Grudniewski ${ }^{2}$, Marta Chodyka $^{2}$, and Jerzy Antoni Nitychoruk ${ }^{2}$ \\ ${ }^{1}$ Warsaw University of Technology, Faculty of Civil Engineering, 16 Lecha Kaczyńskiego Street, \\ 00-637 Warsaw, Poland \\ ${ }^{2}$ State Higher School Pope John Paul II, Faculty of Economic and Technical Sciences, \\ 95/97 Sidorska Street, 21-500 Biala Podlaska, Poland
}

\begin{abstract}
In practice, it is usually assumed that the durability of basic structural elements should not be less than the expected durability of the building. Reinforced concrete constructions, designed and made with quality requirements, are durable. However, each reinforced concrete structure, from the moment it is made, is gradually degraded, and one of the reasons for its destruction is often the corrosion of the concrete and hence the reinforcement. For the long-term use of reinforced concrete constructions, the most important thing is that a thin protective layer on the steel surface protects the reinforcing steel from rusting. One of the most common causes of corrosion in the reinforcement is the damage of this layer as a result of the carbonation of the concrete cover. The rate of carbonation depends on many factors, such as concrete compactness, concentration of $\mathrm{CO}_{2}$, concrete moisture, content of free calcium dioxide, content of mineral additives, etc. When the carbonated layer reaches the steel reinforcement layer, protection of steel from corrosion ceases to exist. The aim of the presented research was to determine the influence of mineral additives used as a compound of concrete on the carbonation of concrete and polymer-cement composites.
\end{abstract}

\section{The phenomenon of carbonation}

Carbonatization is a group of physicochemical transformations of concrete under the influence of long-lasting effects of carbon dioxide. The main causative mechanism of carbonation is the reaction of calcium hydroxide $\mathrm{Ca}(\mathrm{OH})_{2}$, which is one of the hydration products of cement, with atmospheric carbon dioxide $\mathrm{CO}_{2}$, which in the first phase hydrates to carbonic acid, and then forms with portlandite calcium carbonate and water:

$$
\mathrm{Ca}(\mathrm{OH})_{2}+\mathrm{CO}_{2} \rightarrow \mathrm{CaCO}_{3}+\mathrm{H}_{2} \mathrm{O}
$$

Concrete carbonization is a process with a complex effect on concrete and its properties. The main negative effect is the lowering of the alkalinity of concrete, resulting in the loss of

\footnotetext{
* Corresponding author: pawxx@poczta.onet.pl
} 
protective properties of the concrete covering in relation to the reinforcement. This is due to the reaction of basic calcium hydroxide and the formation of neutral calcium carbonate. The result of the carbonation process is the so-called carbon shrinkage caused by the dissolution of calcium hydroxide crystals. In addition to these effects, it was also found that carbonation increases the negative effect of chlorides on the corrosion of the reinforcement $[1,2]$.

\section{Factors influencing concrete carbonation}

The course of the carbonation process may have different rate, which is determined by a number of aspects related to structure, environment and material and technological aspects, the most important of which are: $\mathrm{CO}_{2}$ concentration in air, humidity and air temperature, and concrete composition, including type and amount of binder, value of water-cement ratio, decisive for the tightness of the concrete structure. The course of initial concrete curing is also important. Figure 1 presents factors determining the course of carbonation of concrete and their interrelations. The proposed division is a non-sharp division, and the individual factors are strongly related to cause and effect relationships (e.g. w/c - porosity, cracks - diffusivity etc.), but this division is aimed at identifying factors that should be taken into account when considering carbonation in concrete at various stages of its life, including design, construction and operation.

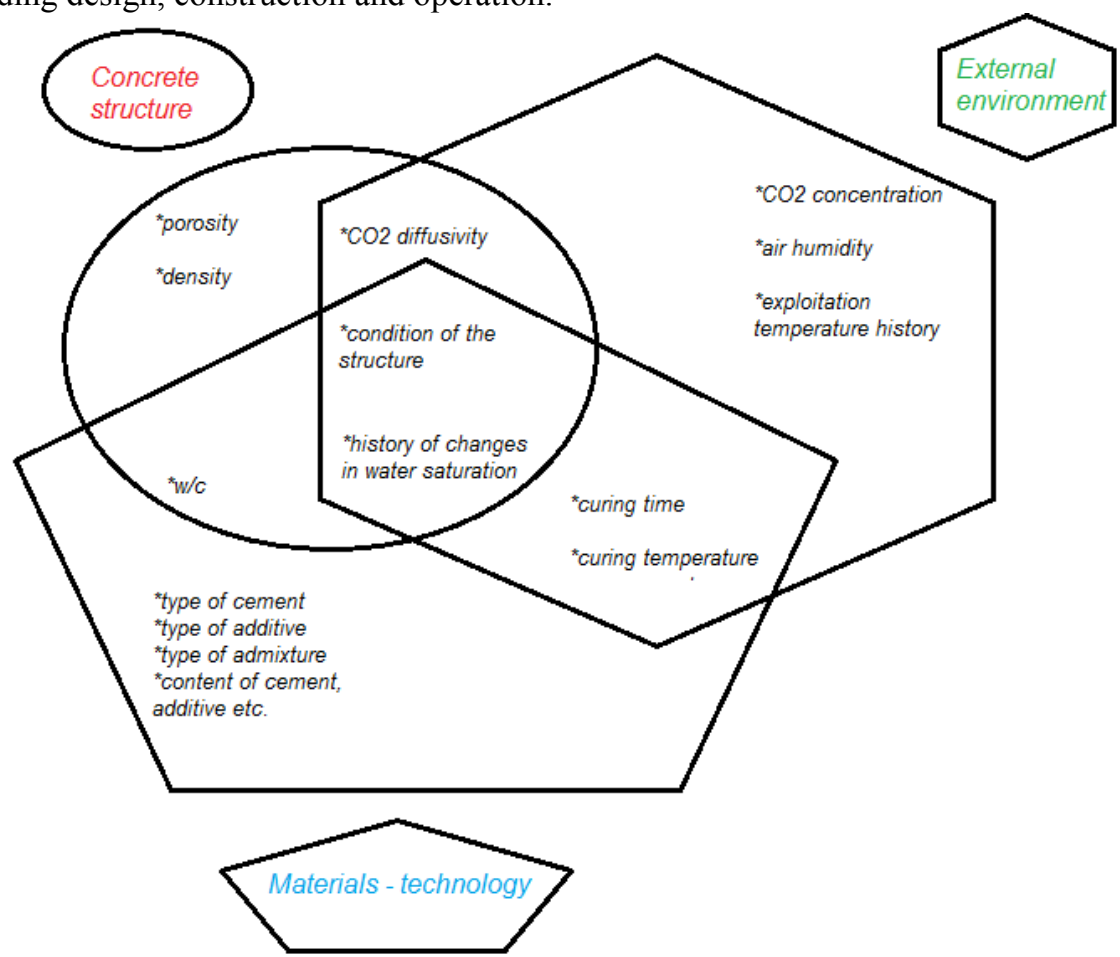

Fig. 1. Factors determining the course of carbonation of concrete and their interrelationships. 


\subsection{Aspects related to the structure of concrete}

The progress of carbonation is significantly related to the possibility of $\mathrm{CO}_{2}$ penetration (diffusion) into the concrete structure. The intensity of this process is related to the tightness of the structure, which is dependent on, among others the water-cement ratio and the technological factors (vibration, plasticizing admixtures, etc.). Dense concrete, with a low content of long capillary pores per unit volume, is a very slow carbonating material. While discussing the results of observations of constructions made of high class concrete, published by Wieczorek [3], it was found that after 10 years of operation, it is difficult to isolate the carbonated layer (about $1 \mathrm{~mm}$ ). Similar observations were made during the tests of retic concrete elements exposed for 10 years in an aggressive urban atmosphere in Warsaw near the Trasa Lazienkowska [3]. The reason for the slow carbonation of such dense concretes is the difficult diffusion of gaseous $\mathrm{CO}_{2}$ into the concrete lagging and the relatively small contact surface of the gas phase containing $\mathrm{CO}_{2}$ and concrete capillaries.

The influence of the cement content on the tightness is connected on the one hand with the amount of calcium hydroxide present in the concrete, binding $\mathrm{CO}_{2}$, on the other hand with the caulking role of the cement itself. Lowering the cement content per unit volume of concrete is usually associated with tilting the water-cement ratio, and thus the density. Hardened cement mortars of domestic CEM I cements usually contain $\sim 17$ to $20 \%$ of $\mathrm{Ca}(\mathrm{OH})_{2}$ resulting from the hydration of clinker minerals. The type of cement and the type and amount of additives also have influence on the rate of carbonation of concrete [3].

Concrete made on the basis of cements containing slag and fly ash additions are characterized by greater susceptibility to carbonation because these additives diminish the calcium hydroxide content even down to zero due to the all chemical reactions. The effect of introducing these additives is therefore similar to reducing the cement content in concrete. In addition, in the presence of higher amounts of fly ash, the content of capillary pores increases, which also significantly accelerates the progress of carbonation of the concrete cover.

The intensity of carbonation of concrete freely exposed to the external environment is higher, the higher the porosity of the concrete, the greater its susceptibility to cracks (the lower the degree of compaction of the concrete mixture, the greater the $\mathrm{w} / \mathrm{c}$ ratio, the worse the concrete curing) and the higher concentration of $\mathrm{CO}_{2}$ in the ambient air.

\subsection{Material and technological aspects}

The water-cement ratio largely determines the structure of the paste in concrete and in this sense has a large impact on the course of carbonation. Low w/c ratio concretes are much less susceptible to carbonation. This fact is the basis of the often stated statement that the rate of carbonation is a function of concrete strength or w/c ratio. In practice, this is true, but neither the value of strength nor the value of the water-cement ratio contain direct information about the microstructure of the surface concrete zone in which $\mathrm{CO}_{2}$ diffusion occurs. Nevertheless, most dependencies describing the course of carbonation take into account the value of the water-cement ratio [5].

The type and amount of binder significantly affect the course of carbonation. Decreasing the cement content limits the amount of $\mathrm{Ca}(\mathrm{OH})_{2}$ capable of reacting with carbon dioxide and impairs the density of the concrete, especially if it increases at the same time. Thus, the lower the cement content, the higher the susceptibility of concrete to carbonation.

The characteristics of cement clinker are also important for the course of carbonation. The slowest progress is in the carbonation of alite cements. Alite hydration is accompanied by the formation of twice as much calcium hydroxide as belite hydration. Therefore, full 
carbonation of successive layers of concrete requires a longer time due to the higher availability of calcium hydroxide in them, and a larger amount of the resulting calcium carbonate better tighten these layers reducing diffusion to deeper layers. Deceleration of the carbonation process is also favored by a higher degree of cement fragmentation, because a faster hydration of cement with a larger specific surface area results in delayed penetration of $\mathrm{CO}_{2}[5,6]$.

The effect of additives to cement and concrete on the course of carbonation is complex $[7,8]$. Type I additives like the fine aggregate do not undergo carbonation, and their role may possibly be to densify the structure and to reduce $\mathrm{CO}_{2}$ diffusion in concrete. The role of type II additives (pozzolanic or with latent hydraulic properties), such as fly ash, microsilica, natural pozzolana and blast furnace slags must be considered in a complex system of interactions. Assessment of the carbonation process of concretes containing such additives should take into account the microstructure of the hardened cement paste $[3,4,5]$. The process of carbonation also depends on the proper curing of the external zone of the concrete. It was found that increasing the period of wet curing from one to three days reduces the depth of carbonation by about $40 \%$. Assessment of the carbonation process of concretes containing fly ash and granulated blast furnace slags should take into account the microstructure of the hardened cement paste. It should be noted that silica fly ash binds a part of $\mathrm{Ca}(\mathrm{OH})_{2}$. As a result the content of calcium hydroxide in the hardened cement paste is lower, and thus the depth of carbonation is higher. It follows that the presence of fly ash accelerates the carbonation process. However, there is also a different effect, namely the formation of a more compact microstructure of the hardened mortar, which reduces the diffusivity and limitation of the carbonation rate [9,10,11].

Concrete curing is part of a full hardening process, which should guarantee the optimal progress of hydration in fresh concrete, towards a durable, impermeable, crack-free concrete. During this initial concrete life, the following requirements should be fulfill: ensuring a proper hardening process, protection against damage caused by drying and protection against thermal shocks.

In the case of polymer-cement composites, the course of the carbonation process depends not only on the selection of appropriate curing, the degree of exposure of the element to carbon dioxide or the age of the composite, as in the case of cement mortars, but also on the type and amount of added polymer modifier. Studies conducted on the polymercement composites showed that with the increase of polymer content, the degree of carbonation increased, and the maximum values were achieved with a polymer content of $10-15 \%$. Despite the increased degree of carbonation of these mortars, corrosion of the reinforcement decreased with the increase of the polymer content, which may be related to the formation of a polymer coating on reinforcing bars protecting the steel surface against carbonation products $[12,13]$.

\section{Experimental study}

The aim of the presented research was to analyze the influence of the mineral additives on the carbonatization of the cement and the polymer-cement composites. The study program consisted of preparing mixtures containing different mineral additive and different content of additive. As a mineral additive calcareous and siliceous fly ash were used. The research program was divided into two parts. The first part investigated the effect of calcareous fly ash on carbonation of concrete. The program assumed the dosage of fly ash in range $17-$ $35 \%$ of cement mass (added as a partial substitution of cement) and the water/cement ratio of the concrete at 0.45 and 0.52 . The Portland cement CEM I 32,5R in accordance with PNEN 196-1[14] and standard aggregate were used. Resistance to carbonation was determined in an accelerated laboratory test. The measurement was carried out on 100x100x100 mm 
samples, which were exposed to $4 \% \pm 0.5 \% \mathrm{CO}_{2}$ at $20 \pm 2{ }^{\circ} \mathrm{C}$ and relative humidity $55 \pm$ $5 \%$, in accordance with EN 12390-12 [15]. The depth of carbonation was measured after 56 days of sample storage in the chamber by applying a phenolphthalein indicator to the fresh fracture surface of the specimen. The sample carbonation depth (dk) is the average of the depths measured on all four sides of the specimen. The results of determination of depth of carbonation $\left(\mathrm{d}_{\mathrm{k}}\right)$ of concrete containing calcareous fly ash are presented in Table 1 .

Table 1. Depth of carbonation of concrete containing calcareous fly ash after 28 days of curing

\begin{tabular}{|c|c|c|c|c|c|}
\hline \multirow{2}{*}{ No } & \multirow{2}{*}{ w/c } & \multirow{2}{*}{ Composition } & \multicolumn{3}{|c|}{ 28-days } \\
\cline { 4 - 6 } & & & $\mathbf{d}_{\mathbf{k}}, \mathbf{m m}$ & $\mathbf{S D}$ & $\mathbf{C V}, \%$ \\
\hline 1 & \multirow{3}{*}{0.45} & $\mathrm{~m} / \mathrm{c}=17.0 \%$ & 6.3 & 1.3 & 20.0 \\
\hline \multirow{2nnyyy}{*}{2} & $\mathrm{~m} / \mathrm{c}=27.0 \%$ & 3.6 & 1.4 & 39.0 \\
\hline & & $\mathrm{m} / \mathrm{c}=35.0 \%$ & 5.2 & 1.3 & 26.0 \\
\hline 4 & \multirow{2}{*}{0.52} & $\mathrm{~m} / \mathrm{c}=20.0 \%$ & 6.8 & 1.4 & 20.0 \\
\hline & & $\mathrm{m} / \mathrm{c}=33.0 \%$ & 8.5 & 1.6 & 19.0 \\
\hline 5 & &
\end{tabular}

$\mathrm{m} / \mathrm{c}$ - mineral additive/cement ratio; SD - standard deviation; $\mathrm{CV}$ - coefficient of variation

Along with the increase in the content of calcareous fly ash in the concrete with a constant $\mathrm{w} / \mathrm{c}$ ratio $=0.45$, an improvement in the resistance to carbonation can be noticed. In this case, the composite 2 containing $27 \%$ of ash was characterized with the highest resistance to carbonation. Surprisingly further increase of the fly ash content results in lower resistance to carbonation. This relationship may suggest that with constant $\mathrm{w} / \mathrm{c}$ there is an optimal ash content that tightens the concrete structure, leading to lower susceptibility to carbonation. In the case of higher $\mathrm{w} / \mathrm{c}$ ratio $=0.52$, with the increase of the amount of calcareous fly ash, a decrease in resistance to carbonation is visible.

The second part of the research program investigated the impact of fly ash on the carbonation of polymer-cement composites. As a mineral additive calcareous and siliceous fly ash was used. As a polymer modifier a water dispersion of styrene-acrylic copolymer was used. The program of the research assumed the dosage of fly ash at 5 and $8 \%$ of cement mass and the dosage of polymer at 5 and $15 \%$ of cement mass. The water/cement ratio of the mortars remained constant at 0.5 . The Portland cement CEM I 42,5R in accordance with PN-EN 196-1[14] and standard sand in accordance with PN-EN 196-1 were used. Resistance to carbonation was determined in an accelerated laboratory test, in accordance with PN-EN 13295 [16]. The measurement was carried out on 40x40x160 mm rectangular samples, which were exposed to $1 \% \mathrm{CO}_{2}$ at $21 \pm 2{ }^{\circ} \mathrm{C}$ and relative humidity $60 \pm 10 \%$. The depth of carbonation was measured after 56 days of sample storage in the chamber by applying a phenolphthalein indicator to the fresh fracture surface of the specimen. The sample carbonation depth $\left(\mathrm{d}_{\mathrm{k}}\right)$ is the average of the depths measured on all four sides of the specimen. The results of determination of carbonation of polymer-cement composites containing fly ashes are presented in Table 2. Standard mortar was used as a reference level.

The polymer-cement composite containing calcareous fly ash showed the least resistance to carbonation after both 28 and 90 days of curing (composite $\mathrm{p} / \mathrm{c}=5.0 \% \mathrm{~m} / \mathrm{c}=$ $5.0 \%$ ). The depth of carbonation of this composite was about twice as high as the carbonation depth of standard mortar and about $15 \%$ greater than the depth of carbonation of the polymer-cement composite containing siliceous fly ash (composite $\mathrm{p} / \mathrm{c}=5.0 \% \mathrm{~m} / \mathrm{c}=$ $5.0 \%$ ). Fly ash addition to the polymer-cement composites has more influence on the carbonation of polymer-cement composites containing lower amount of polymer modifier. 
It should be noted, however, that the differences in the carbonation depth of composites are small.

Table 2. Depth of carbonation of polymer-cement composites containing siliceous fly ash - SFA and calcareous fly ash - CFA after different time of curing (SM - standard mortar - reference level)

\begin{tabular}{|c|c|c|c|c|c|c|c|c|}
\hline \multirow{2}{*}{ No } & \multirow{2}{*}{ Composite } & \multirow{2}{*}{ Composition } & \multicolumn{3}{|c|}{ 28-days } & \multicolumn{3}{|c|}{ 90-days } \\
\hline & & & $\mathbf{d}_{\mathrm{k}}, \mathbf{m m}$ & SD & $\mathrm{CV}, \%$ & $d_{k}, m m$ & SD & CV, \% \\
\hline \multirow{2}{*}{1} & \multirow{2}{*}{ SFA } & $\begin{array}{l}\mathrm{p} / \mathrm{c}=15.0 \% \\
\mathrm{~m} / \mathrm{c}=8.0 \%\end{array}$ & 3.1 & 0.2 & 3.0 & 3.7 & 0.1 & 2.0 \\
\hline & & $\begin{array}{l}\mathrm{p} / \mathrm{c}=5.0 \% \\
\mathrm{~m} / \mathrm{c}=5.0 \%\end{array}$ & 3.8 & 0.1 & 3.0 & 4.2 & 0.1 & 2.0 \\
\hline \multirow{2}{*}{2} & \multirow{2}{*}{ CFA } & $\begin{array}{l}\mathrm{p} / \mathrm{c}=15.0 \% \\
\mathrm{~m} / \mathrm{c}=8.0 \%\end{array}$ & 3.1 & 0.1 & 2.0 & 4.1 & 0.2 & 3.0 \\
\hline & & $\begin{array}{l}\mathrm{p} / \mathrm{c}=5.0 \% \\
\mathrm{~m} / \mathrm{c}=5.0 \%\end{array}$ & 4.5 & 0.2 & 3.4 & 4.6 & 0.1 & 3.0 \\
\hline 3 & SM & $\begin{array}{l}\mathrm{p} / \mathrm{c}=0.0 \% \\
\mathrm{~m} / \mathrm{c}=0.0 \%\end{array}$ & 2.2 & 0.2 & 7.4 & 2.4 & 0.1 & 4.4 \\
\hline
\end{tabular}

$\mathrm{p} / \mathrm{c}$ - polymer/cement ratio; $\mathrm{m} / \mathrm{c}$ - mineral additive/cement ratio; SD - standard deviation; CV coefficient of variation

\section{Conclusion}

On the basis of the research, it can be said that the high content of lime in the ash may suggest that the initial availability of $\mathrm{Ca}(\mathrm{OH})_{2}$ for the carbonation reaction will be high. One can therefore expect a large initial rate of carbonation. On the other hand, the intense course of the pozzolanic reaction will decrease the available calcium hydroxide, while filling the porosity structure with the products of this reaction, which should reduce the $\mathrm{CO}_{2}$ diffusion capacity and inhibit the course of carbonation.

Studies have shown that the calcareous fly ash used in the research as a cement substitute allowed to obtain concrete with very low carbonation depth (from 3.6 to $8.5 \mathrm{~mm}$ after 56 days in $4 \% \mathrm{CO}_{2}$ concentration), further indicate that there is an optimum ash content leading to less susceptibility to carbonation of concrete with low and constant $\mathrm{w} / \mathrm{c}$ ratio.

The polymer-cement composite containing calcium fly ash had the lowest resistance to carbonation after 28 and 90 days of curing (composite $\mathrm{p} / \mathrm{c}=5.0 \% \mathrm{~m} / \mathrm{c}=5.0 \%$ ). The carbonation depth of this composite was about twice as high as the carbonation depth of the standard mortar and about $15 \%$ higher than the carbonation depth of the polymer-cement composite containing silica fly ash (composite $\mathrm{p} / \mathrm{c}=5.0 \% \mathrm{~m} / \mathrm{c}=5.0 \%$ ). The addition of fly ash to polymer-cement composites has a stronger impact on the carbonation of polymercement composites containing a smaller amount of polymer modifier. It should be noted, however, that the differences in the saturation depth of composites are small.

The investigation have shown the important role of mineral additives on resistance to carbonation of cement and polymer-cement base composites. The effect depends strongly on the w/c ratio and dosage of polymer. 


\section{References}

1. L. Czarnecki, P.H. Emmons, Naprawa i Ochrona konstrukcji betonowych/Repair and protection of concrete structures (Polski Cement, Cracow, 2002)

2. L. Czarnecki, P. Woyciechowski, Mat.Bud., 2, 5-7 (2008)

3. G. Wieczorek, Korozja zbrojenia inicjowana przez chlorki lub karbonatyzacje otuliny/ Reinforcement corrosion initiated by chlorides or carbonation of the lagging (Dolnośląskie Wydawnictwo Edukacyjne, Wroclaw, 2002)

4. P. Woliński, G. Adamczewski, P. Woyciechowski, Mat. Bud., 12, 24-25 (2015)

5. A. M. Brandta Ed., Zastosowanie popiołów lotnych z kottów fluidalnych $w$ betonach konstrukcyjnych/ The use of fly ash from fluidized furnaces in structural concrete, PAN, Warsaw, 209-252 (2010)

6. Z. Ściślewski, Ochrona konstrukcji żelbetowych/ Protection of reinforced concrete structures (Arkady, Warsaw, 1999)

7. R. Bucher, P. Diederich, G. Escadeillas, M. Cyr, Cem.Con.Res., 99, 18-29 (2017)

8. A. Leemann, P. Nygaard, J. Kaufmann, R. Loser, Cem.Con.Comp., 62, 33-43 (2015)

9. N.I. Fattuhi, Mat. et Const., 19, 110-125 (1988)

10. R. Więcławski, A. Garbacz, Badanie profilu karbonatyzacji betonów eksponowanych $w$ warunkach naturalnych/Examination of the carbonation profile of concretes exposed in natural conditions (Scientific and Technical Conference "KONTRA", Zakopane, 2004)

11. P. Woyciechowski, Brittle Matrix Composites 10 (ed. A.M. Brandt, J. Olek, M.A. Glinicki, C.K.Y. Leung, Woodhead Publishing Ltd., Institute of Fundamental Technology Research PAS), 115-124

12. A. Xu, S Chandra, Int.J.Cem.Com.Ligh.Con., 10, 49-52 (1988)

13. B. Jaworska, J.J. Sokołowska, P. Łukowski, J. Jaworski, Arch.Civ.Engin., 4, 199-210 (2015)

14. PN-EN 196-1: Cement testing methods - Part 1: Determination of strength

15. prEN 12390-12:2010: Testing hardened concrete - Part 12: Determination of the potential carbonation resistance of concrete: Accelerated carbonation method

16. PN-EN 13295:2005: Products and systems for protection and repair of concrete structures - Test methods - Determination of resistance to carbonation 